\title{
Uma análise do hiperconto Enigma: possibilidades multissemióticas de produção e recepção do gênero
}

\author{
Hellen Teixeira Silva ${ }^{\mathrm{i}}$ \\ Isabela Vieira Lima ${ }^{\text {ii }}$
}

\section{RESUMO}

O presente artigo tem por objetivo analisar as estratégias utilizadas na produção de textos multissemióticos como o hiperconto. Para a fundamentação teórica, recorreu-se a autores como Ferreira e Cardoso (2018), Marcuschi (2004), Santaella (2012) e Spalding (2009). O estudo concentra-se em dois tipos de pesquisa: I) pesquisa bibliográfica, por meio da qual são discutidos os conceitos de hipertexto, multimodalidade e hiperconto; II) pesquisa aplicada, em que é realizada a análise dos elementos hipertextuais e dos recursos semióticos presentes em Enigma (2019). Por meio deste trabalho, foram encontradas limitações e contribuições para o estudo dos hipertextos digitais no contexto da multimodalidade, como, respectivamente: a possível desconfiguração da narrativa do hiperconto em vista do mau funcionamento dos hiperlinks; a potencialidade das semioses na produção de sentidos pelos leitores-interlocutores de hipercontos.

Palavras-chave: Recursos multissemióticos; Multimodalidade; Gênero hiperconto; Hipertextos digitais.

\begin{abstract}
The present article aims to analyze the strategies used in the production of multissemiotic texts such as the hypertale. For the theoretical foundation, authors such as Ferreira e Cardoso (2018), Marcuschi (2004), Santaella (2012) and Spalding (2009). The study focuses on two types of research: I) bibliographical research, through which the concepts of hypertext, multimodality and hypertale are discussed; II) applied research, through which it is performed an analysis of the hypertextual elements and semiotic resources present in Enigma (2019). Throughout this work, there were found limitations and contributions to the study of digital hypertexts in the context of multimodality, as, respectively: the possible deconfiguration of the hypertale narrative caused by
\end{abstract}

\footnotetext{
${ }^{i}$ Mestranda no Programa de Pós-Graduação em Letras pela Universidade Federal de Lavras (UFLA). Graduada em Letras Português/ Inglês e suas Literaturas pela Universidade Federal de Lavras (UFLA/2020). Atua principalmente nos seguintes tópicos: educação em contextos dos multiletramentos, leitura e produção de textos multimodais e multissemióticos, tecnologia e mídia. ORCID: https://orcid.org/0000-0002-8284-7189/ hellen.silva5@estudante.ufla.br

ii Mestranda no Programa de Pós-Graduação em Letras pela Universidade Federal de Lavras (UFLA). Graduada em Letras Português/ Inglês e suas Literaturas pela Universidade Federal de Lavras (UFLA/2019). Atua principalmente nos seguintes tópicos: educação em contextos dos multiletramentos, leitura e produção de textos multimodais e multissemióticos, tecnologia e mídia. ORCID: https://orcid.org/0000-0003-1749-0029 / isabela.lima1 @estudante.ufla.br
} 
malfunction of hyperlinks; the potential of semiosis on production of meanings by hypertale readers-interlocutors.

Keywords: Multissemiotic resources; Multimodality; Hypertale genre; Digital hypertexts.

\section{INTRODUÇÃO}

Ao observar as transformações ocorridas no mundo ao longo das últimas décadas, é possível relacionar grande parte delas aos avanços tecnológicos digitais. Em razão da inserção da sociedade em uma era cada vez mais tecnológica, a forma de comunicar-se, produzir e ler textos também foi modificada. Nesse cenário, apoiados pelas tecnologias digitais da informação e da comunicação (TDIC), e contando com uma vitrine cada vez mais ampla de programas e softwares desenvolvidos para estes fins, os textos tornam-se cada vez mais multimodais e multissemióticos. Diante disso, aspectos como as habilidades de leitura e produção textual também vêm sofrendo alterações.

Desta forma, considerando os impactos da era digital nos textos, é necessário que se investigue como as transformações decorrentes do processo de transmigração do meio impresso para o meio digital refletem em novos parâmetros para a produção e a recepção dos textos. Essas mudanças são resultantes, principalmente, da ampliação das possibilidades de escolha entre múltiplas semioses na produção textual, pois é possível combinar palavra, imagem, som, vídeo, movimento, cores, hiperlinks etc., sendo cada um desses recursos igualmente importantes para a atribuição de sentidos e a construção de uma mensagem.

A começar desses pontos, o presente trabalho tem por objetivo analisar as estratégias utilizadas na produção do hiperconto, texto que se desenvolve no meio digital. O gênero em questão integra o conjunto de hipertextos desse meio, e, assim como ocorre com esses hipertextos, sua constituição se dá a partir de "um conjunto de nós ligados por conexões” (LÉVY, 1993, p. 33) no qual “os nós podem ser palavras, páginas, imagens, gráficos ou partes de gráficos, sequências sonoras” (LÉVY, 1993, p. 33). Em outras 
palavras, o hiperconto constitui-se por seu caráter multimodal e multissemiótico, além da não linearidade característica aos hipertextos.

De início, foi selecionado o hiperconto Enigma (2019) de Tainá Camila dos Santos, analisado de acordo com os recursos utilizados ao longo de sua narrativa. Para tanto, são mobilizadas as percepções teóricas de autores como Costa (2014), Ferreira e Cardoso (2018), Marcuschi (2004), Santaella (2012), Spalding (2009), entre outros. O estudo concentra-se em dois tipos de pesquisa: i) pesquisa bibliográfica, por meio da qual são discutidos os conceitos de hipertexto, multimodalidade e hiperconto; ii) pesquisa aplicada, em que é realizada a análise dos recortes selecionados e são pontuadas as potencialidades e limitações da narrativa digital Enigma, levando em consideração os elementos hipertextuais (hiperlinks) e os recursos semióticos (sons e imagens) em sua constituição, e como esses agem na produção e recepção do texto, a partir das considerações de Hissa (2009), Kress e van Leeuwen (2006) e Xavier (2003).

Inicialmente, será caracterizado o conceito de hipertextos e sua relação com a esfera digital. Na sequência, será realizada uma breve contextualização acerca das transformações que ocorreram nas produções literárias até o surgimento do gênero hiperconto, destacando, ainda, suas principais atribuições. Por fim, será realizada a análise de Enigma, com o intuito de focalizar os recursos utilizados e suas potencialidades para a produção de sentidos.

\section{A HIPERTEXTUALIZAÇÃO DOS PROCESSOS DE LEITURA E ESCRITA}

O processo de hipertextualidade refere-se às múltiplas possibilidades de interação entre produtor-texto-leitor, assim, significa dizer que esses sujeitos (produtor e leitor) possuem liberdade para navegar durante a escrita e a leitura dos textos, não limitando-se a seguir uma estrutura sequencial. Essa característica vem sendo atribuída aos estudos de gêneros digitais e suportes midiáticos, isto porque, a partir da influência da era tecnológica, os textos são acessados por links de navegação e seus hiperlinks ${ }^{1}$ dispostos na tela do computador, do smartphone ou do tablet, permitindo que o usuário faça escolhas de navegação. A título de exemplo, é possível citar a rede social Facebook, na qual seus usuários contam com as opções de selecionar grupos, páginas, chats, 
propagandas, imagens; assim como optar por curtir, comentar e compartilhar esses hiperlinks.

Neste viés, Xavier (2003) considera que a noção de hipertexto pode ser definida como "um construto multienunciativo produzido e processado sobre a tela do computador, que, emergindo no seio da atual Sociedade da Informação, surge como mais novo desafio a ser enfrentado em nossa contemporaneidade" (p. 284). Assim, sua concepção compreende o hipertexto como significativo dentro das plataformas digitais e midiáticas. A partir deste contexto, é considerado o gênero hiperconto um hipertexto da mídia digital, proveniente das tecnologias digitais de informação e da comunicação (TDIC), visto que, assim como outros gêneros impressos que foram transmutados para o meio digital, sofrendo alterações em sua estrutura por meio da incorporação de elementos hipermidiáticos, o gênero em questão foi elaborado a partir de outro gênero, o conto literário, e passou a ser readequado às práticas literárias digitais.

Como exemplo também podem ser citados os gêneros carta e $e$-mail, dado que ambos têm a mesma função comunicativa: permitir a comunicação entre os sujeitos nomeados remetente e destinatário, sendo normalmente utilizados em situações formais de diálogo, possibilitando, além disso, que a comunicação seja facilitada mesmo diante do distanciamento físico entre duas ou mais pessoas.

Entretanto, além da diferença de tempo entre envio e recepção dos textos citados - o e-mail atua de forma instantânea, diferentemente da carta - há ainda que se falar do contraste entre seus elementos composicionais, a citar: a) na carta, a presença de um suporte impresso, que seja o papel ou outros de mesmo tipo; a escrita manuscrita a lápis ou caneta; a inserção de data e até lugar no cabeçalho, entre outros; b) no e-mail, a presença de um suporte digital que seja o computador, o smartphone ou outro; a escrita digital que decorre da digitação em teclas; a não obrigatoriedade de data e lugar, visto que aquela já vem anexada ao e-mail, e essa é representada pelo login (identificação do usuário), que se trata de um hiperlink com domínio do yahoo, outlook ou outros.

Assim, é perceptível como as mudanças mais determinantes entre os gêneros sejam causadas pela necessidade de se adequar o gênero textual impresso ao ambiente digital. Agora, por que se preocupar com essa adequação?

Ao observar as práticas sociais de hoje, percebe-se que a carta acabou por deixar de ser utilizada em ampla escala, sendo vista agora como um gênero antiquado, de outra 
era, mas isso não a torna menos importante. Seu caráter comunicativo ainda está presente em diversos espaços, e possibilitou o surgimento de outros textos digitais, como o chat e a mensagem de texto, assim, é preciso pensar em como os gêneros textuais tendem a acompanhar o progresso evolutivo das tecnologias intelectuais e digitais, repercutindo na urgência em se desenvolver habilidades de escrita e leitura para esses (hiper)textos. De acordo com Ribeiro (2012),

após, aproximadamente, oito séculos de códice, quatro de impressão e um de alfabetização em massa, a invenção do computador, da web e de vários novos dispositivos para fazer uso do texto parece abalar as configurações das tecnologias de ler e escrever (RIBEIRO, 2012, p. 23).

$\mathrm{Na}$ visão da autora, este cenário ainda produz questionamentos de pesquisadores de línguas, educação, entre outros, sobre como essas tecnologias tendem a influenciar os modos de pensar de leitores e autores que vivenciam a era digital. Nesse contexto, inserem-se dois sujeitos, os imigrantes e os nativos digitais. Conforme Prensky (2001), os imigrantes são aqueles que nasceram em um contexto sem a presença da tecnologia digital e precisam aprender de forma constante a usar as plataformas virtuais; enquanto isso, os nativos são aqueles nascidos em meio a era tecnológica, crescendo ao lado dessas novas ferramentas e que, por essa razão, consequentemente sentem mais facilidade para acessar esses espaços e fazer uso de suas estratégias comunicativas.

Nesse sentido, tendo sido o gênero aqui elencado como objeto de estudo - o hiperconto -, foi possível perceber uma série de propostas de construção textual que sustentam mais ou menos a interação desses dois sujeitos citados com a narrativa. Isso porque embora os nativos tenham, em comparação com os imigrantes, maior facilidade para lidar com essas estratégias, ainda existem hipercontos que trazem problemas de execução que irão prejudicar essa interação. Mesmo diante dos conhecimentos apresentados por esses sujeitos, as questões técnicas das quais esses textos dependem, como o navegador utilizado para leitura, a conexão à internet e as configurações de usuário podem dificultar esse contato se, por exemplo, os links e as semioses estiverem desconfigurados, mal distribuídos na página ou apresentando falhas técnicas.

Desse modo, faz-se necessário, por parte do produtor, um trabalho multissemiótico, que pense na etapa de recepção do hipertexto, dado que as características hipertextuais são intrínsecas à execução do gênero hiperconto, e de acordo com Santaella 
(2012), foram determinantes para a criação da literatura digital, o que designou pelo menos três ramos de produção citados por Viires (2006 apud SANTAELLA, 2012):

(a) Todos os textos literários disponíveis nas redes, cobrindo tanto a prosa quanto a poesia que aparecem em sites e blogs de escritores profissionais, em antologias digitais e em revistas literárias online.

(b) Textos literários não profissionais disponíveis na internet, cuja inclusão na análise literária expande as fronteiras da literatura tradicional. [...] Também se incluem aqui as periferias da literatura, como a ficção fanzine, textos baseados em games e narrativas coletivas online.

(c) Literatura hipertextual e cibertextos que incluem textos literários de estrutura mais complexa, explorando várias soluções possíveis de hipertextos e intricados cibertextos multimídia que fazem a literatura misturar-se com as artes visuais, vídeo e música (VIIRES, 2006, p. 2 apud SANTAELLA, 2012, p. 231).

Dentre os três ramos, compreende-se que o hiperconto está localizado no terceiro, posto que esse gênero literário integra, em sua constituição, diferentes semioses, como as citadas (artes visuais, vídeo e música). Assim, é possível perceber como o espaço midiático, além de garantir uma interação cada vez mais espontânea, ainda permite a leitura de diversas semioses imagéticas, verbais e sonoras, ou seja, um espaço amplamente multimodal e híbrido. Essa multimodalidade é caracterizada pela presença de diversos modos de comunicação e diferentes recursos semióticos nos gêneros textuais, permitindo uma maior plurissignificatividade dos textos.

Portanto, considera-se como os recursos hipertextuais e multissemióticos contribuem para a criação de um gênero pertencente à literatura digital, permitindo ainda que sejam realizados estudos cada vez mais sistemáticos acerca de sua produção e recepção nas práticas sociais. De acordo com Santaella (2012), essa literatura digital vai ao encontro das novas condições de produção artística e literária, ou seja, novas relações entre literatura e sujeito. Isso porque, em suas palavras:

[...] o rápido desenvolvimento do vídeo digital e da hipermídia computacional conduziu artistas, músicos, designers, escritores e poetas a explorar em seus ofícios o potencial imaginativo da tecnologia computacional, da remixagem e da ficção hipertextual. Isto porque o teatro de operações do computador permite fazer links, avançar, retroceder, transformar, arquivar, distorcer, gerar e distribuir informação e experiências. Ou seja, criar literatura cuja morfogênese é inseparável dos recursos digitais (SANTAELLA, 2012, p. 233).

Agora, para serem visualizadas as estratégias da narrativa digital do hiperconto, suas potencialidades e limitações, é necessária uma análise voltada ao uso desses recursos 
semióticos citados, bem como é importante que se compreenda como esse gênero digital irá estabelecer diálogos com seu gênero de origem, ou seja, o conto literário.

\section{DO CONTO POPULAR AO HIPERCONTO: DESDOBRAMENTOS MULTISSEMIÓTICOS}

Para tornar possível a análise que se dará a seguir, é necessário explorar alguns conceitos fundamentais para a compreensão daquilo que seriam os hipercontos. Primeiramente, faz-se fundamental discorrer acerca dos gêneros textuais - fenômenos sociais, culturais, históricos e temporais - os quais, de acordo com Marcuschi (2002, p. 10), são como "famílias de textos com uma série de semelhanças". Embora apresentem uma natureza dinâmica e maleável, a qual permite que os gêneros textuais acompanhem e atendam às demandas da comunicação humana e se transformem de acordo com fatores sócio-históricos como, por exemplo, os avanços tecnológicos, nota-se que os gêneros textuais são como padrões pelos quais as atividades de interlocução ocorrem. Significa dizer, portanto, que são como grupos de textos que apresentam características em comum “[...] não só por seu conteúdo (temático) e pelo estilo da linguagem, ou seja, pela seleção dos recursos lexicais, fraseológicos e gramaticais da língua, mas, acima de tudo, por sua construção composicional” (BAKHTIN, 2011, p. 261).

Uma vez conhecido seu caráter flexível, diretamente relacionado aos aspectos socioculturais e às atividades humanas, era possível imaginar então que os avanços tecnológicos causariam algum impacto na forma como os textos são organizados. Embora isso possa parecer novo, Marcuschi (2002) assinala que séculos atrás, com o desenvolvimento da escrita, os gêneros textuais teriam se multiplicado em comparação àqueles que existiam em culturas exclusivamente orais, além de sofrerem grandes transformações. Neste ponto, cabe o exemplo do conto popular. De acordo com o Dicionário de gêneros textuais, de Sérgio Roberto Costa, o conto popular tem como característica a brevidade: história curta, com poucos personagens e ação concentrada em torno desses. Sua origem está nas culturas orais, nas quais a escrita ainda não se fazia presente, sendo "[...] parte de uma literatura oral tradicional, não institucionalizada, transmitida de geração em geração" (COSTA, 2014, p. 86). 
Com o desenvolvimento da escrita, entretanto, surge um novo gênero. Tendo como origem o conto popular, o gênero conto literário apresenta características semelhantes à de seu originário: história curta e centrada em seus poucos personagens, contudo, ele está inserido em uma cultura escrita, fator que, consequentemente, faz dele um novo gênero textual. Costa (2014) chama atenção para outra grande diferença entre esses dois gêneros: a autoria. De acordo com o autor, o conto popular (oral) tem aquilo que seria uma autoria coletiva, visto que aqueles que (re)contam a história têm o poder de modificar, com sutileza, alguns pontos, enquanto o conto literário (escrito) teria um autor definido, o qual controlaria, em certa medida, seu texto. Segundo Costa (2014), o conto popular é feito:

[...] por um tipo de sujeito coletivo, pois é a comunidade que legitima os discursos anônimos da tradição cultural de um povo, produzidos por intérpretes pontuais que, muitas vezes, inovam, atualizam esses discursos, conservandolhes, contudo, a essência, enquanto no conto literário existe um escritor/autor, que é um sujeito que se pode identificar e nomear e tem controle relativo de sua produção (COSTA, 2014, p. 86).

$\mathrm{O}$ autor destaca ainda o fato de ambos apresentarem uma característica sedutora, isto é, atrativa para o ouvinte/leitor. Estabelecida essa relação, na qual é possível perceber que a passagem da oralidade para a escrita já marca uma significativa transformação nas formas de comunicação, serão discutidas, na sequência, as implicações da transmigração do conto literário, produzido em ambiente impresso, para o hiperconto, proveniente do ambiente digital.

Nesse sentido, faz-se necessário refletir acerca dos avanços tecnológicos relacionados à comunicação, e de como eles modificaram as atividades comunicativas em diversos aspectos, como o surgimento de novos gêneros textuais. De acordo com Marcuschi (2002),

esses novos gêneros não são inovações absolutas, quais criações ab ovo, sem uma ancoragem em outros gêneros já existentes. O fato já fora notado por Bakhtin [1997] que falava na "transmutação" dos gêneros e na assimilação de um gênero por outro gerando novos. A tecnologia favorece o surgimento de formas inovadoras, mas não absolutamente novas (MARCUSCHI, 2002, p. 2).

Marcuschi (2002) chama a atenção para o fato de que, por estarem inseridos em ambientes digitais, os novos gêneros contam com a associação de diversos tipos de 
semioses: verbais, sonoras, imagéticas e até mesmo o movimento, recursos que não estavam totalmente disponíveis no meio impresso. Como exemplo, observam-se os gêneros conto literário - que já fora aqui caracterizado - e o hiperconto.

De acordo com Marcelo Spalding, autor de Um estudo em vermelho, o primeiro hiperconto lançado no Brasil, em outubro de 2009, o termo hiperconto refere-se a uma "versão do conto para a Era Digital" (SPALDING, 2009, s./p.). De acordo com o escritor, o hiperconto:

[...] sendo ainda um conto, de tradição milenar, requer narratividade, intensidade, tensão, ocultamento, autoria. $\mathrm{O}$ texto, naturalmente, ainda deve ser o cerne do hiperconto, preservando seu caráter literário. Mas um bom hiperconto será capaz de aproveitar as ferramentas das novas tecnologias para potencializar a história que conta [...]. Imagens, em movimento ou não, áudios, hiperlinks, interatividade e quebra da linearidade são apenas algumas das possibilidades do hiperconto (SPALDING, 2009, s./p).

Conforme o autor, o hiperconto continua sendo um texto literário, ficcional e sedutor, que apresenta uma narrativa curta, cujas principais características são a combinação entre diferentes modos semióticos - escrita, oralidade, som, imagem, movimento etc. - a interatividade com seus leitores e a não linearidade. A respeito disso, torna-se primordial a discussão acerca da multimodalidade.

É necessário estabelecer que a "multimodalidade [...] não é uma teoria, mas sim uma característica constituinte de qualquer texto" (GUALBERTO; PIMENTA; SANTOS, 2018, p. 18). Segundo a perspectiva adotada pelas autoras supracitadas, todo texto é multimodal, mesmo aquele sem imagens em sua constituição, sendo exclusivamente verbal, pois "outras formas de representação - como a diagramação da página (layout), a cor e a qualidade do papel, o formato e a cor (ou cores) das letras, a formatação do parágrafo etc., interferem na mensagem a ser comunicada" (DESCARDECI, 2002, p. 20-21). Nesse sentido, a teoria da Semiótica Social (SS), preconizada por Hodge e Kress (1988), defende que, além dos signos verbais, outros recursos também desempenham um importante papel para a produção e a atribuição de sentido dos textos, conferindo aos outros signos a mesma relevância do modo verbal.

Dessa maneira, é possível depreender que os modos e recursos semióticos não tratam apenas de oralidade, escrita ou imagem, pois são muito mais abrangentes: referemse ao layout, aos sons, às cores, à disposição, à diagramação, à gesticulação, à entonação, 
à tipografia etc., elementos importantes para a construção de sentidos. Há de se destacar ainda que a multimodalidade "[...] pressupõe que os recursos são socialmente modelados através do tempo para se tornarem geradores de sentido" (DIONISIO; VASCONCELOS; SOUZA, 2014, p. 49).

Assim, no que diz respeito aos meios digitais e às tecnologias voltadas para a comunicação, verifica-se que a variedade de semioses tem aumentado graças ao desenvolvimento de softwares e a programas de edição de imagem, texto, som e vídeo, os quais permitem e ampliam a possibilidade de combinação entre diferentes recursos semióticos. Como consequência, os textos estão mais multissemióticos, sendo necessário ressaltar que, assim como sugerido pela SS, as escolhas feitas pelos autores e produtores dos textos não são aleatórias: para cada signo escolhido, existe um objetivo baseado na cultura e nos propósitos comunicativos, sugerindo interpretações já estipuladas. Como viés de confirmação da presença dessas semioses citadas nos hipercontos e sua importância para o processo de interpretação e recepção desses, há pesquisas como a de Alves et al. (2019), que demonstram como as semioses e os links da narrativa são geradoras de sentidos e permitem o interesse pela leitura de alunos da educação básica. Esses alunos se encontram imersos nos ambientes digitais, inclusive, a maior parte senão todos os alunos das escolas de hoje são nativos digitais, pois nasceram no contexto tecnológico digital e já fazem uso dessas ferramentas. Por isso, é de suma importância que os educadores elaborem atividades e materiais didáticos voltados para essa realidade virtual da sociedade, pois é ela que define as práticas vivenciadas por essas crianças e adolescentes. De acordo com os autores:

[...] é necessário que a escola trabalhe a diversidade de gêneros, que se apresentam nos diferentes suportes a fim de tornar os discentes leitores proficientes. Portanto, compreende-se que os gêneros oriundos do ambiente virtual também precisam ser trabalhados na sala de aula, uma vez que as tecnologias permeiam as relações humanas. É exigindo, ao aluno de hoje, novas práticas de letramento, distante das tradicionais disseminadas pela escola, ele precisa lidar com textos multimodais e multissemióticos, por exemplo (ALVES et al., 2019, p. 5).

Assim, para o trabalho com o gênero hiperconto, seja na pesquisa ou produção desse, seja na aplicação em sala de aula, é importante considerar a orientação de Spalding (2009), isto é, que a mera transferência do conto impresso para o meio digital não transforma o texto em um hiperconto, pois esse tem características próprias que o 
diferenciam de seu antecessor e caracterizam-no como produto da era digital (movimento, hiperlink, recursos sonoros etc.). Acerca disso, de acordo com Wendorff (2020, p. 185; tradução nossa), "uma literatura digital não representa histórias tradicionais que foram digitalizadas [...] mas sim, trabalhos de origem digital que são por definição objetos digitais, criados a partir do uso de computadores e que também requerem os computadores para serem lidos/recepcionados" ${ }^{2}$.

Ainda nesse sentido e em conformidade com Gomes (2010), é importante também ressaltar que somente estar no meio eletrônico ou digital não assegura ao texto o caráter hipertextual, uma vez que "os links que integram a organização composicional de um hipertexto têm que estar no texto exercendo uma função textual, e não apenas navegacional" (CARDOSO; FERREIRA, 2018, p. 96 apud GOMES, 2010, p. 32).

O hiperconto Um estudo em vermelho, assim como o Enigma, de Tainá Camila dos Santos, apresenta, ao longo da história, pontos nos quais o leitor deverá fazer escolhas que irão definir o próximo passo dos personagens. Por meio de hiperlinks, é dada ao leitor a possibilidade de participar da construção da história, direcionando esta para determinados acontecimentos - e desfechos - pré-estabelecidos pela autora. A oportunidade de definir o caminho do protagonista oferece uma maior interação entre leitor e hiperconto, como bem orientam Cardoso e Ferreira (2018, p. 97), "a leitura e a produção de hipercontos acontecem de forma totalmente interativa e não linear, permitindo múltiplos finais e uma maior interação do texto com o leitor”.

Além disso, destaca-se um dos recursos que colaboram para a imersão do leitor na narrativa Um estudo em vermelho, a citar: a trama é desenvolvida a partir de uma troca de e-mails, o leitor é convidado a cadastrar, logo no início, seu e-mail pessoal e seu nome em um espaço destinado para este fim. A partir de então, nome e e-mail cadastrados passam a fazer parte do corpo das mensagens trocadas, como é possível verificar nas figuras 1, 2 e 3 abaixo: 
Figuras 1, 2 e 3: Elementos hipertextuais do hiperconto Um estudo em vermelho
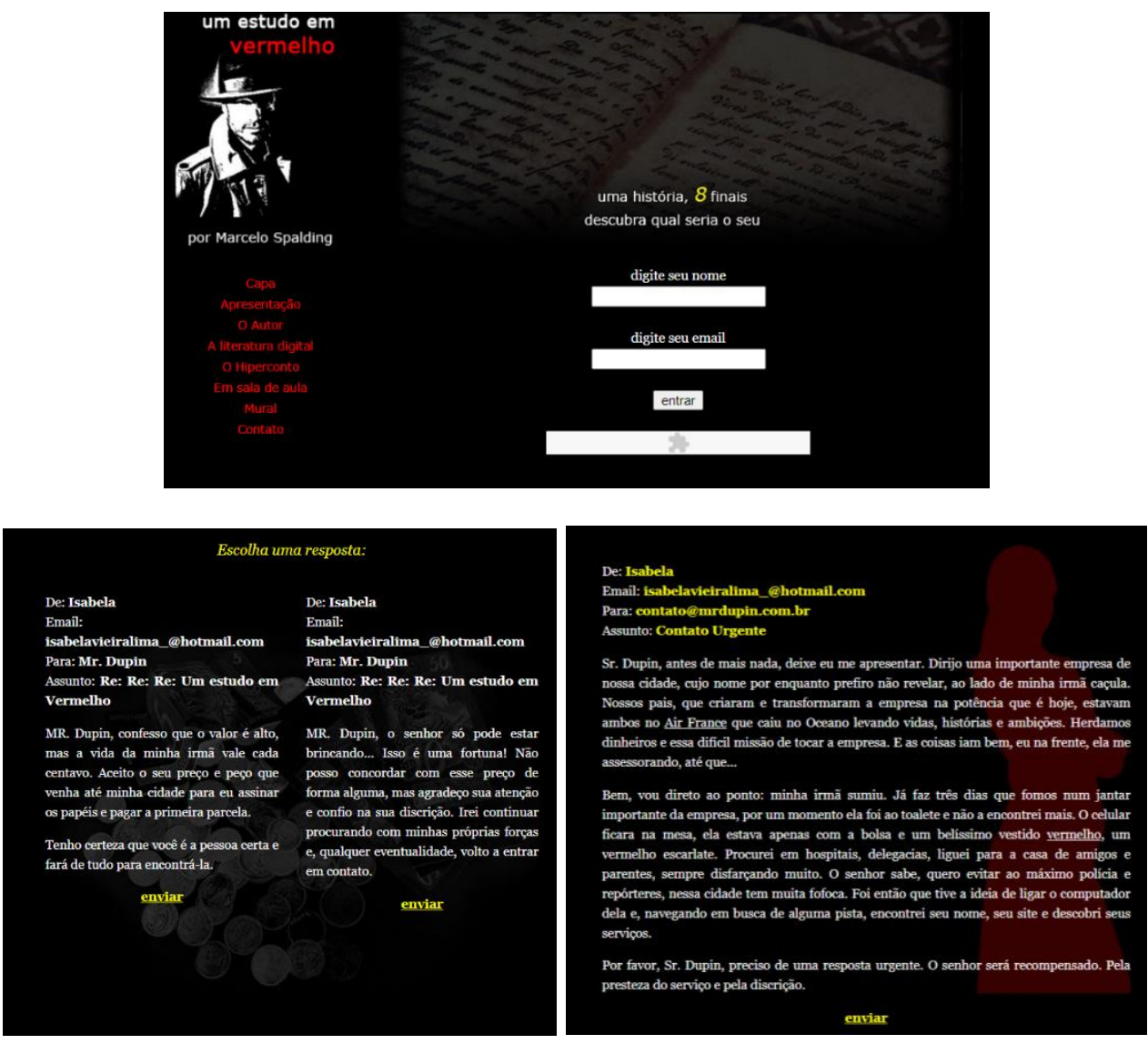

Fonte: http://www.artistasgauchos.com.br/_estudovermelho/. Acesso em: 25 de janeiro de 2021.

A importância de destacar esse elemento dá-se pelo fato de que apenas no meio digital essa interação é possível, pois em um conto impresso seria inviável que o autor disponibilizasse versões contendo $e$-mail e nome de cada um de seus leitores. Importante ressaltar que, caso não possua um endereço eletrônico, o leitor poderá inserir no espaço destinado a esta informação um e-mail qualquer, fictício, para ser utilizado apenas durante a leitura do hiperconto.

A seguir, serão destacadas mais algumas características relacionadas ao gênero hiperconto por meio da análise de Enigma (2019).

\section{APONTAMENTOS PARA A ANÁLISE DO HIPERCONTO ENIGMA}


O hiperconto Enigma ${ }^{3}$ é um texto desenvolvido pela autora Tainá Camila dos Santos no âmbito do PROLICEN (Programa de Bolsas da Licenciatura), em 2019, e está disponível no portal Literatura Digital ${ }^{4}$ junto a outros textos literários e digitais.

Como método de análise do hiperconto, foram selecionadas algumas capturas de tela. A análise será realizada a partir dos elementos hipertextuais como os hiperlinks e os recursos semióticos, tais como os sons e as imagens, de forma a mostrar como se dá a recepção desse texto. Serão pontuadas, ainda, algumas limitações percebidas no hiperconto, bem como suas contribuições em relação ao estudo dos hipertextos digitais no contexto da multimodalidade. Em síntese, são apresentadas as categorias de análise no quadro abaixo:

Quadro 1: Categorias de análise

\begin{tabular}{|l|l|l|}
\hline \multicolumn{1}{|c|}{ Categorias } & \multicolumn{1}{|c|}{ Teóricos } & \multicolumn{1}{c|}{ Critérios } \\
\hline Hiperlinks & $\begin{array}{l}\text { XAVIER, 2003 e } \\
\text { HISSA, 2009 }\end{array}$ & $\begin{array}{l}\text { Funções extuais, } \\
\text { navegacionais } \\
\text { informacionais. }\end{array}$ \\
\hline Sons & XAVIER, 2003 & $\begin{array}{l}\text { Adequação das escolhas } \\
\text { sonoras ao gênero; } \\
\text { contribuição para a imersão } \\
\text { do leitor no cenário da } \\
\text { narrativa, }\end{array}$ \\
\hline Imagem e tipografia & $\begin{array}{l}\text { KRESS; } \\
\text { LEEUWEN, 2006 VAN }\end{array}$ & $\begin{array}{l}\text { Saliência: grau de destaque } \\
\text { dos elementos, produzindo } \\
\text { hierarquia entre esses }\end{array}$ \\
\hline
\end{tabular}

Fonte: Elaborado pelas autoras (2021)

Enigma conta a história de uma família que se muda para uma mansão nas proximidades de um grande e misterioso labirinto. A narrativa é composta por elementos que pertencem aos gêneros suspense e terror, desta forma, o plot inicial é constituído pelo desaparecimento de uma das crianças dessa família. Os desfechos da história são determinados pelos caminhos que a mãe e a irmã irão seguir para encontrar a menina. A depender da escolha do leitor, o desfecho pode, ainda, resultar na morte das duas personagens ou mesmo da criança. Nesse contexto, os elementos hipertextuais e 
semióticos observados apresentam relação com a temática enigmática da narrativa, a começar pela capa do hiperconto (figura 4).

Figura 4: Capa de Enigma

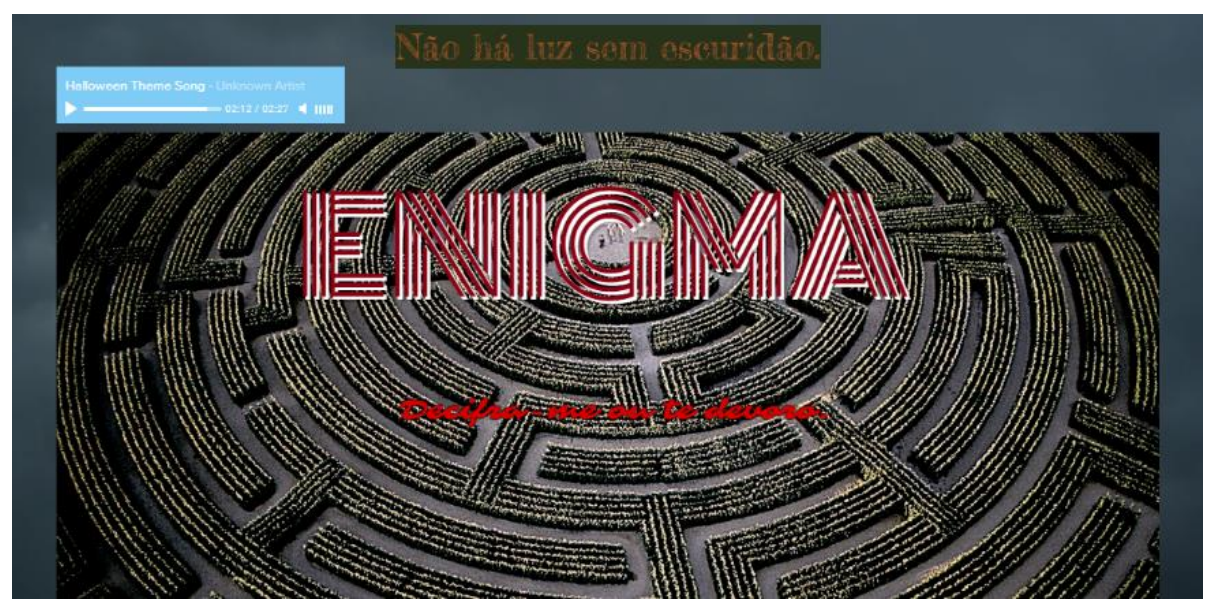

Fonte: hiperconto Enigma (2019)

A saliência é um processo semiótico que diz respeito ao destaque dado aos diferentes elementos visuais de uma imagem. Quanto maior o grau de destaque, mais atenção o leitor dará para aquele elemento, portanto, a saliência define o caminho de leitura percorrido na recepção do texto multissemiótico e a hierarquia entre as informações dadas. Esse destaque pode ser realizado pelo diferente tamanho entre os elementos, diferença de foco, nitidez e brilho, além do contraste entre tons e cores (KRESS; VAN LEEUWEN, 2006). Assim, acerca da tipografia dos signos verbais títulos e subtítulos - destacados na figura, tem-se o seguinte: o título "Enigma" escrito nas cores vermelha e branca, em tamanho maior e fonte de imprensa em caixa alta (Caps Lock); o subtítulo "decifra-me ou te devoro" em vermelho vivo, tamanho pequeno e fonte cursiva; a frase de apresentação "não há luz sem escuridão" em amarelo e fundo verdemusgo, tamanho médio e fonte de imprensa.

Quanto a esses três elementos verbais, é possível dizer que o título apresenta o maior grau de saliência não apenas por seu tamanho, que é relativamente maior em relação aos outros elementos, como também pelas cores escolhidas (vermelho e branco), as quais permitem um contraste visual com o plano de fundo (labirinto) que não compromete sua leitura. Em contraparte, os outros dois elementos verbais, o subtítulo e a frase de apresentação, são produzidos com cores, fontes e tamanho que diminuem sua saliência. Isso porque o subtítulo, apesar de estar em uma cor extremamente chamativa 
(vermelho vivo), não contrasta de forma satisfatória com o plano de fundo (labirinto), ficando apagado na visualização, além de conter uma fonte tipográfica cursiva de difícil leitura, dado que o espaçamento entre as letras é bastante curto, trazendo a sensação de embaraçamento. Enquanto isso, a frase de apresentação está apresentada em uma fonte tipográfica e tamanho relativamente maior e de fácil leitura, mas as cores escolhidas (amarelo e verde-musgo) não produzem um contraste com o fundo de céu azulacinzentado, mostrando-se, também, apagadas em relação aos outros elementos.

No tocante à saliência, também é possível tratar do som incorporado a essa página de apresentação e em todas as outras páginas da narrativa. A cor escolhida para a visualização da trilha sonora (azul-piscina) realiza uma ruptura no caminho de leitura durante a recepção deste texto, isso porque a trilha sonora é um fator de ambientação para que o leitor se sinta imerso na história e em seu gênero (suspense/terror), mas a forma como é apresentada pode fazer com que essa imersão seja comprometida em partes, pois apresenta uma cor de destaque maior que todos os outros elementos visuais, inclusive os signos verbais, apresentando o grau de saliência máxima. Assim, o leitor interage mais curiosamente com esse elemento do que com os outros. Nesse caso, compreende-se que a cor da trilha sonora deve concordar com a do plano de fundo de cada página, para assim tratar-se de um fator de ambientação, isto é, um fator de segundo plano.

Mas, além disso, essa trilha sonora também apresenta limitações quanto a sua funcionalidade dentro da narrativa. Embora o hiperconto traga uma trilha sonora adequada e muitíssimo bem escolhida para cada um de seus momentos, o que colabora para a imersão do leitor na história, dado que o hipertexto, por seu caráter multimodal, oferece "a possibilidade de acessar e absorver informações, multi-sensorial e sinestesicamente, momento em que todos os modos enunciativos (texto verbal, som e imagem) ali presentes funcionam, cooperativamente, para a efetivação da leitura" (XAVIER, 2003, p. 258), os efeitos sonoros não são reproduzidos instantaneamente à abertura das páginas da narrativa. Compreende-se que isso pode acontecer em decorrência de cada sistema operacional de computador, suas configurações etc., portanto, não foi possível afirmar se o recurso sonoro não foi corretamente configurado ou se os computadores utilizados no momento de análise impediram que isso acontecesse.

Essa questão é importante, pois a opção "play" vem apenas ao final da página (exceto pela primeira página do hiperconto). Pela lógica de leitura ocidental, cujo sentido 
é de cima para baixo e da esquerda para a direita, o leitor passará por toda a página e só encontrará a opção de som quando tiver acabado sua leitura. Em função da falta de instantaneidade da trilha sonora observada, o ideal seria que essa opção fosse apresentada bem ao início de cada página, para que, assim, o leitor pudesse reproduzir a música manualmente, caso fosse de seu interesse. Com relação a isso, Santos (2015) aponta que:

[...] os recursos multissemióticos, como fotografias, imagens em movimento, desenhos, vídeos, sons diversos, músicas, gráficos, integram-se à materialidade linguística, ressignificando a experiência do leitor com os textos escritos, ampliando os efeitos de sentido e os significados do texto (SANTOS, 2015, p. 28).

Agora, no que concerne aos hiperlinks disponibilizados para a escolha do leitor, é possível observar que os produtores optaram pelo uso de links de substituição em toda a narrativa, pois, a cada clique realizado, a página é atualizada de modo a apresentar o novo conteúdo, não sendo necessária a abertura de novas guias no servidor utilizado, pois “o nó de destino ao qual o link leva substitui o nó de início" (HISSA, 2009, p. 6). Nota-se, ainda, que não há um padrão: o leitor deve navegar por toda a página até encontrar as opções ou os locais específicos nos quais os hiperlinks estão distribuídos. Há momentos em que eles são apresentados quando o leitor passa o mouse pelos signos verbais, e outros nos quais os hiperlinks estão escondidos em imagens, entretanto, em todos os casos, eles são percebidos como "parte do texto ou da imagem e estão embutidos na própria informação" (HISSA, 2009, p. 5), característica que faz com que eles sejam classificados como links implicados. Existe, inclusive, um momento em que uma só imagem guarda dois hiperlinks diferentes - a ser discutido mais à frente.

Mesmo quando se trata do signo verbal, a tipografia utilizada não é sempre a mesma, entretanto, não foi possível perceber o padrão ou propósito para essa variação. Embora tenha sido explicado nas instruções que o leitor deve procurar os elementos clicáveis, "ao mesmo tempo que pode ajudar o hiperleitor a construir o sentido do hipertexto, o hiperlink também pode atrapalhar sua concentração e distraí-lo para outras questões periféricas" (XAVIER, 2003, p. 288), e, por tal motivo, pode ser interessante padronizar esses elementos, ao menos em relação à tipografia, para que o leitor saiba de imediato que precisará fazer uma escolha e localize mais facilmente as opções. 
Figuras 5 e 6: Tipografia
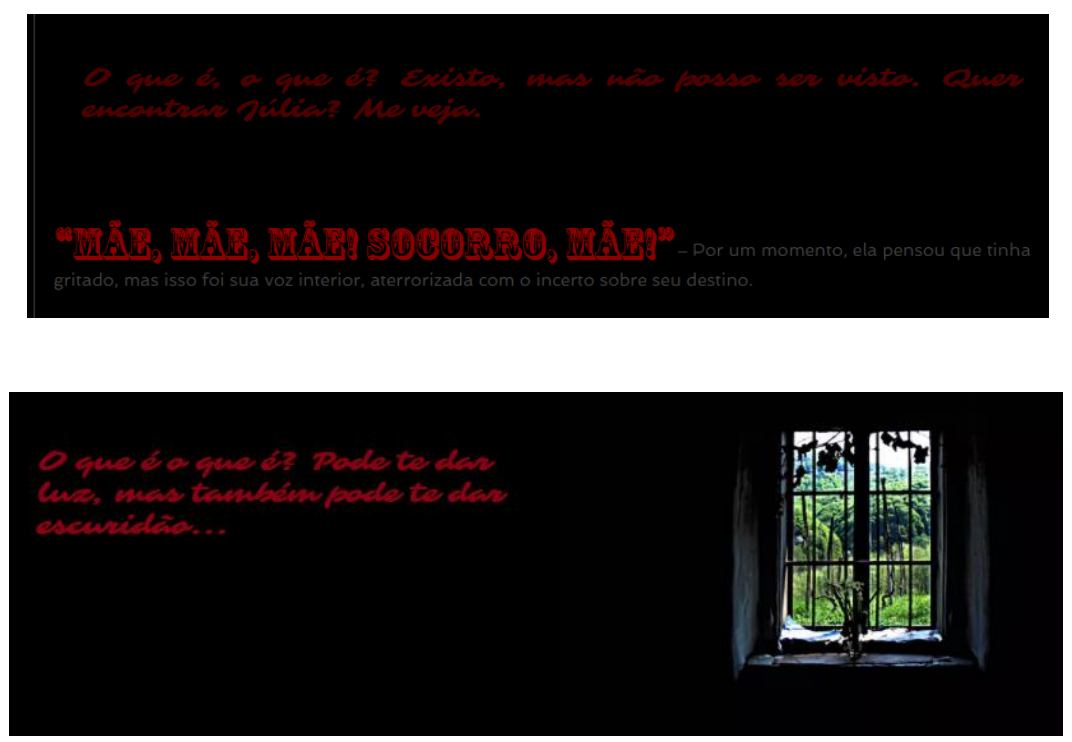

Fonte: hiperconto Enigma (2019)

$\mathrm{Na}$ figura 5, as duas opções escritas em vermelho apresentam hiperlinks. De acordo com a classificação apresentada por Hissa (2009), links que são apresentados sublinhados, utilizando-se de cores, formatação e tipografia diferentes da do restante do texto são classificados como links textuais. Entretanto, na figura 6, isso não ocorre, já que mesmo tendo a mesma tipografia de uma das opções clicáveis da página anterior, o hiperlink está escondido na imagem da janela. Ainda conforme a autora supracitada, quando os links são "representados por outras semioses que não as formas nominais: ícones, gráficos, botões, imagens, mapas etc.” (HISSA, 2009, p. 4), eles recebem a classificação de links gráficos. Dessa forma, assim como as figuras 7, 8 e 9 apresentadas na sequência, a figura 6 , ao dispor de partes clicáveis, carrega o que ficou conhecido por link gráfico.

Como essas telas podem aparecer na sequência (a depender de qual opção será selecionada na primeira imagem), o leitor pode esperar que tanto na imagem quanto na frase exista um hiperlink. É importante pensar que esse aspecto pode ter sido planejado pela autora/produtora do hiperconto e apresenta razão para ser assim, não sendo, então, aleatório. O intuito desses apontamentos é levantar hipóteses, mas de modo algum desvalorizar o trabalho realizado em Enigma.

Acerca da saliência dessas figuras, é importante mencionar que todas as páginas de Enigma (exceto a capa) são compostas por um fundo preto e os signos verbais em 
vermelho vivo ou cinza claro, como é possível ver nas figuras 5 e 6 . Desse modo, a análise aqui realizada se aplica a todas as outras partes da narrativa. Em relação ao grau de saliência dos componentes que constituem essas figuras, têm-se os seguintes aspectos: fundo em preto escuro; os signos verbais que representam hiperlinks e narração em vermelho vivo, ora em fonte de imprensa ora em fonte cursiva, ambos em tamanho médio; os signos verbais que representam apenas a narração em cinza claro, fonte tipográfica de imprensa e tamanho reduzido.

Considerando o destaque, acredita-se que os signos verbais em vermelho tenham o maior grau de saliência, dado que produzem um grande contraste entre o vermelho e o preto que se encontra ao fundo. Nesse caso, ao contrário do que ocorre na capa da narrativa, as fontes Imprensa e Cursiva são de fácil leitura em decorrência do fundo liso apresentado. Entretanto, como já mencionado acima, não é possível dizer o porquê de a narração apresentar duas cores (vermelho e cinza-claro), o que pode confundir o leitor, fazendo-o acreditar que todos os elementos em vermelho sejam hiperlinks.

Além disso, mesmo que a maior parte da narração esteja em outra cor, no cinzaclaro, o texto acaba apresentando pouco contraste em relação ao fundo preto, ainda mais por seu tamanho extremamente reduzido. Consequentemente, esses fatores criam um grau de saliência baixo, comprometendo, de certa maneira, a leitura. De acordo com Kress e van Leeuwen (2006, p. 201; tradução nossa), “independentemente do lugar em que os elementos estejam posicionados, a saliência pode criar uma hierarquia de importância entre eles, selecionando alguns deles como mais importantes, mais dignos de atenção do que outros". Desse modo, a baixa saliência atribuída ao texto em cinza claro pode comprometer o valor e a importância concedidos a eles, mesmo sendo parte fundamental do hiperconto. 
Figuras 7, 8 e 9: entrada do labirinto e a seleção para continuar a narrativa
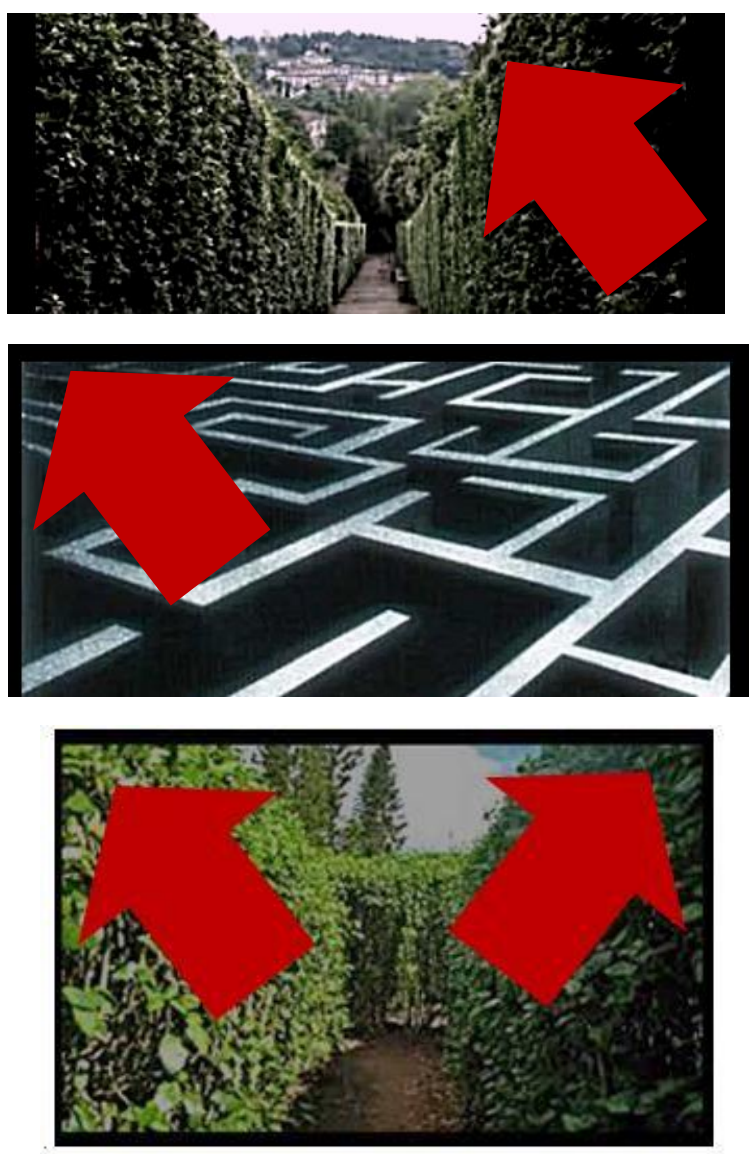

Fonte: Enigma (2019)

Em determinado momento, o leitor tem a opção de seguir para um labirinto (figura 7). Nessa imagem, há a presença de um link gráfico no centro. Ao selecionar esse link, o leitor é direcionado para "dentro" do labirinto (figura 8), sendo que, nesse caso, o link gráfico encontra-se apenas no lado esquerdo, em uma parte reduzida da imagem - seta elaborada pelas autoras para visualização. Na figura 9, o hiperconto sugere: "Vire à direita para continuar", mas caso o leitor obedeça ao comando, as três personagens ficam presas para sempre no labirinto. Entretanto, não há nada que indique ao leitor que virar à direita seja uma "pegadinha", não há nenhuma pista ou sugestão da autora, o que ocorre é que ao navegar com o mouse por cima da imagem da encruzilhada, o lado esquerdo também aparece como opção clicável (link gráfico), assim como o lado direito - setas elaboradas pelas autoras para visualização.

Portanto, o processo de recepção do texto Enigma leva, ainda, em consideração outro fator substancial: a curiosidade do leitor. É a partir da curiosidade que se torna 
possível encontrar o link escondido na figura 9. Caso a leitura seja realizada com rapidez e pouca atenção aos detalhes, o leitor irá perder partes da narrativa, podendo determinar o fim da história logo naquele momento e levando o leitor a se sentir frustrado com o desfecho. Spalding (2009) explica esse fenômeno a partir da atitude que o leitor tem diante da narrativa e de suas escolhas, em suas palavras:

[...] vale lembrar que há autoria na escolha dos finais e sua relação com o caminho percorrido, não sendo os finais de forma alguma aleatórios. Por exemplo, se o leitor foi sempre intempestivo nas suas escolhas, acabará com um final violento, talvez até morrendo (SPALDING, 2009, s.p.).

Assim, não somente as escolhas dos finais não são aleatórias, como também a escolha da autora de incorporar links escondidos na narrativa, tendo como objetivo novos rumos e potencialidades de imersão.

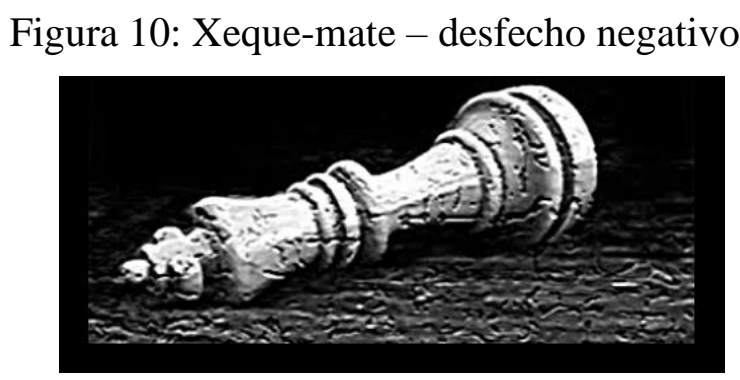

Fonte: hiperconto Enigma (2019)

Acerca das imagens presentes no hiperconto, tem-se a imagem de uma peça de xadrez caída (figura 10), que aparece com os dizeres "xeque-mate" em todos os desfechos negativos, ou seja, nos quais as três personagens (ou somente Júlia) morrem. É possível observar a importância do elemento para a leitura de quem receberá esta parte da narrativa, isso porque, de acordo com a saliência, a peça de xadrez em preto e branco produz um contraste alto em relação ao fundo completamente escuro. O interessante é observar como a proposta de tons nesse momento é outra, pois ao contrário das demais cores utilizadas no hiperconto, como o vermelho vivo dos hiperlinks, o branco e o cinza da peça do jogo de xadrez, estas duas últimas cores normalmente associadas a um caráter neutro, também permitem um grau de saliência maior para esta imagem em comparação aos outros elementos da página. Dessa forma, é possível estabelecer contraste por meio 
das cores de diversas maneiras, a depender da escolha, da seleção e do propósito do produtor do texto.

Nesse sentido, a utilização de um efeito em preto e branco pode remeter ainda ao significado da morte, em que haveria o fim da vida e das cores que a compõem, e mais especificamente, nesse caso, representa o fim da narrativa para o leitor. Assim, considerase que os elementos composicionais visuais estão ainda atrelados à produção de sentidos e não somente à simples ilustração. Em concordância à Kress e van Leeuwen (2006),

\begin{abstract}
A composição não é apenas uma questão de formalidade estética, mera percepção ou para chamar a atenção dos leitores (embora também seja isso); como também permite a ordenação dos elementos significativos em textos coerentes e faz isso por maneiras que seguem requisitos pertencentes às estruturas específicas dos modos e essas produzem significado (KRESS; VAN LEEUWEN, 2006, p. 203; tradução nossa).
\end{abstract}

Vale ressaltar que essa produção de significados se dá também em decorrência da cultura na qual o texto é produzido e consumido, ou seja, conforme estruturas específicas. No Brasil e em vários outros países, o preto é utilizado para simbolizar a morte, a perda, o vazio. Entretanto, é sabido que em outras regiões do mundo, como na Índia, a cor utilizada para isso é a branca. É importante, portanto, que os produtores dos textos respeitem e conheçam a cultura com a qual estão lidando, considerando, além de suas preferências, aquilo que melhor se adequa à mensagem que se busca construir.

Figura 11: adivinhação e a lâmpada fazendo referência ao enigma

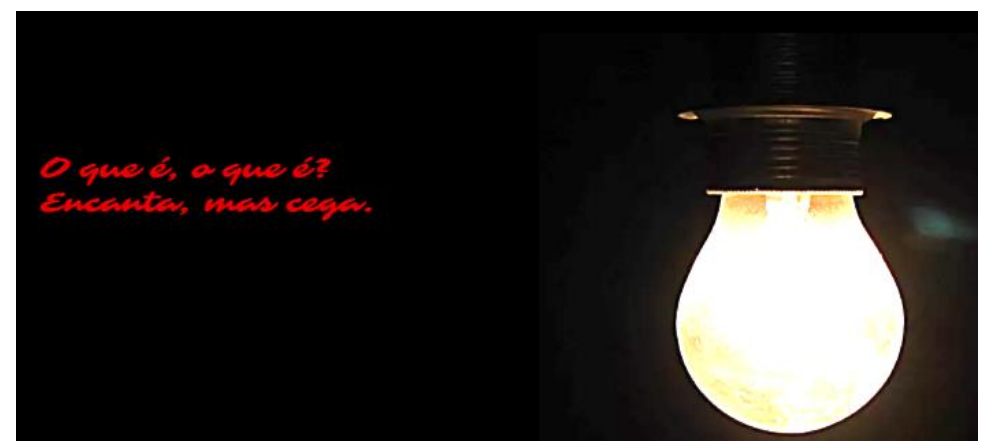

Fonte: hiperconto Enigma (2019)

Ao final, o leitor precisa interpretar a adivinhação (figura 11) e optar pelo caminho da escuridão se quiser salvar as três, pois a luz é aquilo que cega. Caso as personagens 
não obedeçam à adivinhação, as três morrem. Para a compreensão dessa consequência, a produtora não somente faz referências verbais acerca da luz ao longo da narrativa, como também utiliza a adivinhação e a lâmpada da figura em questão.

Como é dito na própria adivinhação "O que é, o que é? Encanta, mas cega”, o leitor precisa compreender as pistas verbais e visuais deixadas ao longo de Enigma. Nesse caso, a forte incidência de brilho na imagem da lâmpada produz um alto grau de saliência e busca concordar com o que é proposto pelo enigma, pois embora a luz seja algo belo, que encanta, seu excesso pode trazer complicações aos olhos humanos e causar pontos de cegueira. O contraste alcançado por meio da forte luz, representada na figura 11, torna-se ainda maior pelo fato de o fundo ser completamente preto, atribuindo à luz todo o destaque. Nas palavras de Kress e van Leeuwen (2006),

\footnotetext{
Essa saliência, novamente, não é objetivamente mensurável, mas resulta de uma interação complexa, uma relação de troca complexa entre uma série de fatores: tamanho, nitidez de foco, contraste entre tons (áreas de alto contraste de tons - por exemplo, fronteiras entre preto e branco - tem alta saliência), contrastes de cores (por exemplo, o contraste entre cores fortemente saturadas e "suaves" ou o contraste entre vermelho e azul [...] (KRESS; VAN LEEUWEN, 2006, p. 202; tradução nossa).
}

Assim, a partir da análise do hiperconto Enigma (2019) e de todas as considerações realizadas até aqui, foi possível perceber que, com o uso das tecnologias digitais de informação e comunicação (TDIC), as possibilidades de combinação entre diferentes semioses permitiram que fossem adicionados aos textos elementos que ampliaram a imersão e a interação do leitor com o texto. Por meio da combinação entre elementos verbais, imagéticos, sonoros e hiperlinks, o hiperconto Enigma convida o leitor a contribuir para a construção da história e proporciona a ele uma maior ambientação com o gênero da narrativa e com o cenário no qual o evento narrado se desenvolve, promovendo uma atmosfera de terror e suspense que contribui para que a leitura seja mais prazerosa e eficaz, no sentido de alcançar os propósitos de seu gênero, visto que outros sentidos - visuais e sonoros - também são explorados.

Enquanto isso, foram observadas algumas limitações no que concerne à escolha desses mesmos elementos, a citar: a cor chamativa para a trilha sonora e o fato de ela não ser reproduzida automaticamente, as cores e fontes das tipografias presentes na capa de 
apresentação, as cores e o tamanho de fonte da tipografia da narração, as quais podem dificultar a leitura em ambos os casos, hiperlinks que acabam por distrair o leitor.

Por fim, é possível considerar a mensagem proposta pela produtora do hiperconto: em uma história de suspense/terror, a cor preta do fundo faz alusões às sensações de medo e escuridão, mas ocorre uma mudança surpreendente ao final da narrativa, em que a escuridão torna-se um meio seguro para manter a vida, enquanto a luz torna-se um fator de fatalidade.

\section{CONSIDERAÇÕES FINAIS}

Conforme a discussão teórica e as análises aqui levantadas, depreende-se que as plataformas digitais são espaços que vêm permitindo o acesso de diferentes sujeitos, sejam esses escritores, desenhistas, bolsistas e pesquisadores à criação artística e literária visando diversos objetivos comunicativos. Por meio da discussão acerca da hipertextualidade dos textos digitais, é possível perceber como os gêneros mobilizados dentro das práticas sociais estão cada vez mais dotados de recursos de leitura e escrita da era digital, influenciando, consequentemente, em pesquisas das áreas de educação, política, arte etc., pois esses recursos hipertextuais estão relacionados aos modos como os sujeitos mobilizam as diferentes linguagens na comunicação.

O hiperconto é um gênero que se mostrou constituinte dessa nova era de interação entre autor-texto-leitor, no qual o leitor pode fazer escolhas e construir a narrativa em um fenômeno de coautoria. Dessa forma, o gênero, para além de um texto hipertextual, consiste em um texto pertencente à literatura digital, que traz novas compreensões acerca da produção e da recepção dos gêneros literários. Por compreender ainda a mobilização de diferentes recursos semióticos ao longo de sua construção linguística e narrativa, o hiperconto potencializa a produção de sentidos pelo leitor, gerando interpretações conforme o uso de signos contextuais, ou seja, refletindo os significados de uma cultura e geração.

A multimodalidade não se refere a uma simples inclusão de semioses nos textos, mas sim a como os produtores pensam e planejam a produção multissemiótica, fazendo escolhas que irão colaborar para a produção de sentidos. Pensar no estudo dos hipertextos digitais como o hiperconto é pensar que esses textos dependem ainda das tecnologias digitais, que exigem dos sujeitos diversos níveis de conhecimento técnico. Então, para 
que o leitor consiga interagir com esse tipo de texto, é necessário um planejamento do produtor quanto à recepção do hiperconto e às escolhas mais adequadas para a efetiva imersão do leitor.

Consideram-se necessárias, portanto, discussões acerca dos textos hipertextuais e multimodais da era digital, sejam hipercontos, videoclipes, videoanimações, e-mails, lives, pois participarão de forma cada vez mais constante da vida social dos sujeitos. Ademais, eles representam, em sua constituição, estratégias semióticas, linguísticas e discursivas da linguagem, afetando, principalmente, nos processos de produção e recepção desses textos. Esses sujeitos escritores/leitores imersivos atuam agora na forma de agir da sociedade, e sua relação com os ambientes midiáticos e digitais acarretam o desenvolvimento da leitura e da escrita dentro e fora da cibercultura.

\section{Referências}

ALVES, A. et al. An applicability of hypercontos in the portuguese classes. Research, Society and Development, v. 8, n. 6, p. 1-15, 2019. DOI: 10.33448/rsd-v8i6.963. Disponível em: https://rsdjournal.org/index.php/rsd/article/view/963. Acesso em: 19 out. 2021.

BAKHTIN, Mikhail. Estética da criação verbal. Trad. PEREIRA, M. E. G. G.. São Paulo: Martins Fontes, 2011, p. 275-326.

CARDOSO, Pedro Henrique; FERREIRA, Helena Maria. A produção de hipercontos: potencialidades para a formação de professores em uma perspectiva dos multiletramentos. Revista Crátilo, Patos de Minas, v. 11, n. 1, p. 91-106, jul. 2018.

COSTA, Sérgio Roberto. Dicionário de Gêneros Textuais. 3. ed. Belo Horizonte: Autêntica, 2014.

DESCARDECI, Maria Alice Andrade de Souza. Ler o mundo: um olhar através da semiótica social. ETD - Educação Temática Digital. v. 3, n. 2., p. 19-26, 2002.

DIONISIO, Angela Paiva; VASCONCELOS, Leila J.; SOUZA, Maria M. de. Multimodalidades e leituras: funcionamento cognitivo, recursos semióticos, convenções visuais. Recife: Pipa Comunicação, p. 41-77, 2014.

GOMES, Luiz Fernando. Hipertextos multimodais: leitura e escrita na Digital. Jundaí: Paco Editora, 2010.

GUALBERTO, Clarice Lage; PIMENTA, Sônia Maria de Oliveira; SANTOS, Záira Bomfante dos. Leitura e produção textual no contexto acadêmico: 
práticas e reflexões a partir da multimodalidade e da semiótica social. In: (orgs.). Multimodalidade e ensino: múltiplas perspectivas. São Paulo: Pimenta Cultural, 2018. p. 13-35.

HISSA, Débora. Uma proposta de classificação dos links hipertextuais a partir de critérios navegacionais e informacionais. In: III Encontro Nacional sobre Hipertexto. Belo Horizonte. 2009, p. 1-10.

HODGE, Robert; KRESS, Gunther. Social Semiotics. Crambridge: Polity Press, 1988.

KRESS, G. R.; VAN LEEUWEN, T. Reading Images: The Grammar of Visual Design. London: Routledge, 1996 [2006].

LÉVY, Pierre. As tecnologias da inteligência. O futuro do pensamento na era da informática. Trad. Carlos Irineu da Costa. Rio de Janeiro: 34, 1993. (Coleção TRANS)

MARCUSCHI, Luiz Antônio et al. Gêneros textuais: definição e funcionalidade. Gêneros textuais e ensino. Rio de Janeiro: Lucerna, v. 20, 2002.

MARCUSCHI, L.A; XAVIER, A.C.S. Hipertextos e gêneros digitais: novas formas de construção do sentido. Rio de Janeiro. Lucerna, 2004.

PRENSKY, Marc. Nativos digitais, imigrantes digitais. On the horizon, v. 9, n. 5, p. 1-6, 2001.

RIBEIRO, Ana Elisa. Novas tecnologias para ler e escrever: algumas ideias sobre ambientes e ferramentas digitais na sala de aula. Belo Horizonte: RHJ, 136 p. 2012.

SANTAELLA, Lúcia. Para compreender a ciberliteratura. v. 8, n. 2. Texto Digital: Florianópolis, v. 8, n. 2, p. 229-240, 2012. DOI: 10.5007/1807-9288.2012v8n2p229

SANTOS, Marcos Celírio dos. Entre contos e hipercontos: uma proposta de trabalho integrado para o desenvolvimento dos multiletramentos. 2015. 280 f. Dissertação (Mestrado) - Curso de Letras, Universidade Federal de Minas Gerais, Belo Horizonte, 2015.

SANTOS, Tainá C. Enigma. Literatura Digital. 2019. Disponível em: https://santostainac.wixsite.com/enigma. Acesso em: 31 ago. 2021.

SPALDING, Marcelo. Um estudo em Vermelho. Artistas Gaúchos. 2009. Disponível em: http://www.artistasgauchos.com.br/_estudovermelho/?pg=2591. Acesso em: 31 ago. 2021.

WENDORFF, Anna. The "Narrative Turn" in Literature. Observations on Digital Works. Art Inquiry. Recherches sur les arts, v. 22, p. 183-192, 2020.

XAVIER, Antônio Carlos. Hipertexto e intertextualidade. Cadernos de Estudos Linguísticos, v. 44, p. 283-290, 2003. 


\title{
Recebido em: 31/08/2021
}

Aceito em: 19/10/2021

\begin{abstract}
${ }^{1}$ Aqui, considera-se como link qualquer elemento de hipermídia formado por um trecho de texto (URL) ou por um elemento gráfico que permita a exibição de páginas da web, enquanto os hiperlinks são elementos constituintes desse, como, por exemplo, imagens, vídeos, textos e qualquer outro objeto clicável.

${ }^{2}$ No original: "digital literature does not mean traditional stories which have become digitalised [...] but works of a digital origin which are by definition digital objects, created using a computer and requiring a computer to be read".

${ }^{3}$ Link para o hiperconto: <https://santostainac.wixsite.com/enigma〉. Acesso em: 31 de agosto de 2021.

${ }^{4}$ Link para o portal: < http://www.literaturadigital.com.br/?pg=25014>. Acesso em: 31 de agosto de 2021.
\end{abstract}

